\title{
Nocturnal ventilatory support in patients with cystic fibrosis: comparison with supplemental oxygen
}

\author{
D. Gozal
}

Nocturnal ventilatory support in patients with cystic fibrosis: comparison with supplemental oxygen. D. Gozal. (CERS Journals Ltd 1997.

ABSTRACT: Progressive deterioration of lung function in cystic fibrosis $(\mathrm{CF})$ patients may lead to significant hypoxaemia and hypercapnia, especially during sleep.

The effects of bilevel noninvasive positive pressure nasal mask ventilation (NIPPV) on respiration and sleep were compared to those of low-flow oxygen therapy in six CF patients (mean \pm SD age $22.3 \pm 4.7$ yrs, with severe lung disease (forced expiratory volume in one second (FEV1) $29.4 \pm 3.4 \%$ predicted).

Compared to the control night, NIPPV and oxygen therapy significantly improved overall night-time oxygen saturation during both rapid eye movement (REM) and non-rapid eye movement (NREM) sleep stages. However, significant increases in transcutaneous $\mathrm{CO}_{2}$ tension occurred during oxygen therapy, while NIPPV markedly improved alveolar ventilation during all sleep states. Sleep architecture and arousals remained unchanged during NIPPV and oxygen therapy treatment nights.

We conclude that noninvasive positive pressure ventilation improves sleep-related hypoxaemia and hypercapnia in severe cystic fibrosis patients without affecting sleep. The long-term compliance and benefits of noninvasive positive pressure ventilation remain unclear.

Eur Respir J 1997; 10: 1999-2003.
Constance S. Kaufman Paediatric Pulmonary Research Laboratory, Depts of Paediatrics and Physiology, Tulane University School of Medicine, New Orleans, LA, USA.

Correspondence: D. Gozal, Section of Paediatric Pulmonology, Dept of Paediatrics, SL-37, Tulane University School of Medicine, 1430 Tulane Avenue, New Orleans, LA 70112, USA

Keywords: Hypercapnia, hypoxaemia, nasal mask ventilation, sleep

Received: January 71997

Accepted after revision June 221997

The author is supported in part by a grant from the National Institutes of Health. HD01072, by a Bureau of Maternal and Child Health Training Grant, MCJ-229163, and by a Career Development Award from the American Lung Association.
With advancing lung disease, patients with cystic fibrosis (CF) may develop clinically significant hypoxaemia and hypercapnia during sleep, particularly during rapid-eye movement (REM) sleep [1,2]. Domiciliary administration of supplemental oxygen improves nocturnal oxygenation in these patients, but it either does not modify or significantly aggravates concomitant alveolar hypoventilation [3, 4]. Respiratory stimulants such as theophylline may ameliorate certain aspects of gas exchange during sleep in CF but also markedly disrupt sleep architecture [5]. Thus, noninvasive positive pressure ventilation (NIPPV) has been advocated in patients with chronic obstructive pulmonary disease (COPD) in an effort to improve diurnal quality of life, provide respiratory muscle rest, and prevent or reverse the cardiovascular sequelae of intermittent or chronic hypoxaemia and hypercapnia [6].

In a recent study of seven CF patients, REGNIS et al. [4] demonstrated significant improvements in nocturnal oxygenation during both REM and non-REM (NREM) sleep when nasal continuous positive airway pressure (CPAP) was administered [4]. Sleep architecture was unaffected and transcutaneous $\mathrm{CO}_{2}$ tension $\left(P \mathrm{tc}, \mathrm{CO}_{2}\right)$ measurements were not different during nasal CPAP and control nights. However, these investigators did not compare CPAP with supplemental oxygen.

The purpose of the present study was to compare the respiratory and sleep benefits derived from the use of NIPPV or night-time low-flow oxygen in CF patients with moderate to severe lung disease and significant gas exchange abnormalities during sleep.

\section{Materials and methods}

\section{Subjects}

Six subjects with CF, aged 13-28 yrs (mean \pm SD, $22.3 \pm 4.7 \mathrm{yrs}$ ) completed the study. Two additional patients did not tolerate NIPPV and had to be excluded from the study. Patients with CF were recruited from the Section of Paediatric Pulmonology at Tulane Hospital for Children. All patients had pulmonary symptoms, signs, and radiological changes consistent with $\mathrm{CF}$, and were diagnosed by pilocarpine iontophoretic sweat chloride tests. All subjects with CF were receiving pancreatic enzymes, vitamin supplements, nebulized bronchodilators and deoxyribonuclease (DNAase) (Pulmozyme, Genentech, CA, USA) at the time of the study, and some were also receiving inhaled or intravenous antibiotics. Subjects with CF were studied when clinically stable, either as out-patients or at the end of a 2-3 week hospital stay. Informed consent was obtained from each subject and from his or her legal guardian when appropriate, and the study was approved by the Institutional Review Board.

\section{Pulmonary function testing}

All patients underwent pulmonary function testing in the pulmonary function laboratory at the Tulane University Medical Center, located at sea level (mean atmospheric pressure $101.3 \mathrm{kPa}(762 \mathrm{mmHg})$ ). All measurements for each subject were performed on the same day. The vital capacity (VC) and its subdivisions were 
measured from a slow exhalation with a wedge spirometer (Collins DSIIa, Braintree, MA, USA). The best forced VC, forced expiratory volume in one second (FEV1), mean forced expiratory flow during the middle half of forced vital capacity (FEF25\%-75\%), and maximal expiratory flow-volume curves obtained from forced expiration into the wedge spirometer, were selected and corrected for body temperature and ambient pressure, saturated with water vapour (BTPS). Functional residual capacity was measured with a body pressure plethysmograph (SensorMedics 2800 Autobox, Yorba Linda, CA, USA) by the method of DuBors et al. [7]. Residual volume (RV) and total lung capacity (TLC) were calculated, and the RV/ TLC ratios determined from the actual values. Individual test results were analysed and considered abnormal if they were greater than \pm 2 SD from available reference values appropriate for age, height and gender [8].

\section{Overnight polysomnography}

Subjects were studied for $8 \mathrm{~h}$ in a quiet, darkened room with an ambient temperature of $24^{\circ} \mathrm{C}$. Patients received their regular medications, and no drugs were used to induce sleep. The following parameters were measured: chest and abdominal wall movement by respiratory inductance plethysmography (Respitrace, Ambulatory Monitoring, Ardsley, NY, USA); cardiac frequency by electrocardiograph (ECG); airflow with a thermistor (Physitemp; Clifton, NJ, USA); $P$ tc, $\mathrm{CO}_{2}$ using heated $\left(43^{\circ} \mathrm{C}\right)$, calibrated transcutaneous electrodes (SensorMedics Transcend Cutaneous Gas System; SensorMedics, Yorba Linda, CA, USA); and arterial oxygen saturation $\left(\mathrm{Sa}_{\mathrm{a}} \mathrm{O}_{2}\right)$ by pulse oximetry (Nellcor N 200; Nellcor Inc., Hayward, CA, USA), with simultaneous recording of the pulse waveform. Capillary blood gas samples were drawn during wakefulness prior to and following completion of each sleep study. $P \mathrm{tc}, \mathrm{CO}_{2}$ values were considered reliable only if $P \mathrm{tc}, \mathrm{CO}_{2}$ and $\mathrm{CO}_{2}$ tension $\left(\mathrm{PCO}_{2}\right)$ values were within $10 \%$ of each other. The electro-oculogram (EOG), two-channels of electroencephalogram (EEG: C3/A2 and C4/A1), and chin electromyogram (EMG) were also monitored.

Scoring of respiratory variables during sleep was performed in $60 \mathrm{~s}$ epochs as described previously [9-11]. Apnoea was defined as cessation of air flow for $10 \mathrm{~s}$ or longer even if unaccompanied by concomitant oxygen desaturation. Apnoeas of less than $10 \mathrm{~s}$ duration were also included if they lasted for more than one respiratory cycle and were associated with oxygen desaturation of $>4 \%$. Obstructive events were defined as above in the presence of respiratory effort as evidenced from continued thoracoabdominal motion, while in central apnoea no evidence of thoracic or abdominal motion was present. The mean $\mathrm{Sa}_{2} \mathrm{O}_{2}$ (after validation by an adequate pulse waveform signal) and $P_{\mathrm{tc}, \mathrm{CO}_{2}}$ values recorded for each $60 \mathrm{~s}$ were retained for analysis. Nonrespiratory variables were also scored using standard criteria [12]. Total sleep time (TST) was defined as total recording time minus the sleep latency. Arousals were calculated by dividing the total number of arousals by TST.

\section{Protocol}

Each patient participated in the three designated sleep studies within a 15 day period. All patients were initially studied in room air. If clinically significant hypoxaemia and/or hypercapnia were present in this initial study, they were randomly assigned to receive NIPPV or supplemental oxygen in the second night. For the third night, the remaining treatment modality was administered.

After a mask-fitting session, patients were encouraged to wear the NIPPV nasal mask (Respironics Inc., Murraysville, PA, USA) during daytime hours for habituation purposes. To determine the oxygen flow or NIPPV to be employed during the sleep study nights, several trials were conducted during 1-2 $\mathrm{h}$ afternoon naps while measuring $\mathrm{Sa}_{2} \mathrm{O}_{2}$ and $\mathrm{Ptc}_{\mathrm{tc}} \mathrm{CO}_{2}$. During these sessions, one patient did not tolerate application of the nasal mask while the other patient refused to continue pressure titration procedures on the basis of marked breathing discomfort. For the six patients who completed the study, the mean flow of supplemental oxygen blended into the NIPPV circuit was $2.2 \pm 0.5 \mathrm{~L} \cdot \mathrm{min}^{-1}$, and mean airway pressures were titrated to $16.3 \pm 1.9$ and $5.3 \pm 1.1 \mathrm{cmH}_{2} \mathrm{O}$ for inspiratory (IPAP) and expiratory (EPAP) pressures, respectively. In addition, the NIPPV ventilator (BiPAP STD; Respironics Inc., Murraysville, PA, USA) was set in the assist/control mode in all patients, with a respiratory back-up frequency of 12 breaths $\cdot \mathrm{min}^{-1}$, a IPAP:EPAP duration ratio of 1 , and a $F \mathrm{I}, \mathrm{O}_{2}$ of $21 \%$.

\section{Data analysis}

Results are presented as mean \pm SD. Data from control, oxygen therapy and NIPPV nights were compared using paired t-tests or the nonparametric multi-independent group Kruskal-Wallis H-test as appropriate. A p-value of less than 0.05 was considered significant.

\section{Results}

Demographic, anthropometric, and pulmonary function data for the six CF patients studied are shown in table 1 . In general, all patients had moderate to severe lung disease with FEV1 ranging $25-35 \%$ of predicted values. All patients had $\mathrm{Pa}_{\mathrm{a}} \mathrm{O}_{2}$ below $9.0 \mathrm{kPa}(68 \mathrm{mmHg})$ and two were slightly hypercapnic during wakefulness $\left(P \mathrm{a}, \mathrm{CO}_{2}>6 \mathrm{kPa}(45 \mathrm{mmHg})\right)$.

During sleep in room air (control), patients demonstrated significant oxyhaemoglobin desaturation (fig. 1) and alveolar hypoventilation (fig. 2). Oxygen desaturation and $P \mathrm{tc}, \mathrm{CO}_{2}$ elevation were more likely to occur during REM epochs (table 2), and nadir $\mathrm{Sa}_{2} \mathrm{O}_{2}$ (range 62-67\%) and highest $P \mathrm{tc}, \mathrm{CO}_{2}$ (range $8.9-9.9 \mathrm{kPa}$ ) were recorded during REM sleep. There were no significant obstructive apnoeic events during control or treatment nights.

Administration of supplemental oxygen was associated with significant improvements in mean oxygen saturation throughout the night (fig. 1), and this effect was present during both REM and NREM sleep (table 2). A significant increase in REM density occurred during oxygen therapy $(\mathrm{p}<0.02$, Kruskal-Wallis H-test). NREM duration, sleep latency and arousal index were similar to those recorded during control night (table 2). Improved oxygenation in these patients was accompanied by 
significant increases in $P$ tc, $\mathrm{CO}_{2}$, which encompassed both REM and NREM sleep (table 2; fig. 2).

As mentioned in the Materials and methods section, two patients were excluded because they did not tolerate NIPPV. In the remaining six patients, no particular problems were reported regarding mask fitting or pres- sure titration procedures. Four of the six patients preferred the use of supplemental oxygen to NIPPV, despite morning headache being present in two patients upon awakening following oxygen therapy. As with oxygen therapy, NIPPV did not significantly modify sleep latency, total sleep time, NREM density, or arousal index

Table 1. - Individual anthropometric and pulmonary function measurements in six cystic fibrosis (CF) patients

\begin{tabular}{|c|c|c|c|c|c|c|c|c|c|c|c|c|}
\hline $\begin{array}{l}\text { Patient } \\
\text { No. }\end{array}$ & $\begin{array}{l}\text { Age } \\
\text { yrs }\end{array}$ & $\begin{array}{l}\text { Gender } \\
\mathrm{M} / \mathrm{F}\end{array}$ & $\begin{array}{l}\text { Weight } \\
\mathrm{kg}\end{array}$ & $\begin{array}{l}\text { Height } \\
\mathrm{cm}\end{array}$ & $\begin{array}{l}\mathrm{BMI} \\
\mathrm{kg} \cdot \mathrm{m}^{-2}\end{array}$ & $\begin{array}{c}\mathrm{FVC} \\
\% \text { pred }\end{array}$ & $\begin{array}{l}\text { FEV1 } \mathrm{F} \\
\% \text { pred }\end{array}$ & $\begin{array}{c}\text { FEF25\%-75\% } \\
\% \text { pred }\end{array}$ & $\begin{array}{c}\text { TLC } \\
\% \text { pred }\end{array}$ & $\underset{\%}{\mathrm{RV} / \mathrm{TLC}}$ & $\begin{array}{l}\mathrm{Pa}_{\mathrm{a}, \mathrm{O}_{2}} \\
\mathrm{mmHg}\end{array}$ & $\begin{array}{l}{\mathrm{Pa}, \mathrm{CO}_{2}}_{2} \\
\mathrm{mmHg}\end{array}$ \\
\hline 1 & 13 & $\mathrm{~F}$ & 34.0 & 134 & 18.9 & 45.6 & 32.2 & 16 & 112 & 58 & 63 & 40 \\
\hline 2 & 16 & M & 45.0 & 149 & 20.3 & 42.8 & 34.4 & 14 & 104 & 61 & 67 & 47 \\
\hline 3 & 17 & M & 48.8 & 156 & 18.4 & 38.9 & 27.6 & 9 & 98 & 60 & 54 & 48 \\
\hline 4 & 21 & $\mathrm{~F}$ & 51.0 & 144 & 24.6 & 42.2 & 29.8 & 7 & 89 & 57 & 49 & 43 \\
\hline 5 & 23 & F & 36.6 & 148 & 16.7 & 36.5 & 25.3 & 9 & 123 & 64 & 53 & 42 \\
\hline 6 & 19 & M & 49.2 & 163 & 18.5 & 37.6 & 26.9 & 7 & 119 & 67 & 55 & 44 \\
\hline Mean & 18.2 & - & 49.4 & 149 & 19.6 & 40.6 & 29.4 & 10.3 & 107.5 & 61.2 & 56.8 & 44 \\
\hline SD & 3.6 & - & 6.8 & 10 & 2.7 & 3.5 & 3.4 & 3.7 & 12.9 & 3.8 & 6.8 & 3 \\
\hline
\end{tabular}

M: male; F: female; BMI: body mass index; FVC: forced vital capacity; FEV1: forced expiratory volume in one second; FEF25\%-75\%: mean forced expiratory flow during the middle half of FVC; TLC: total lung capacity; RV: residual volume; $\%$ pred: percentage of normal predicted value. $1 \mathrm{mmHg}=0.133 \mathrm{kPa}$.

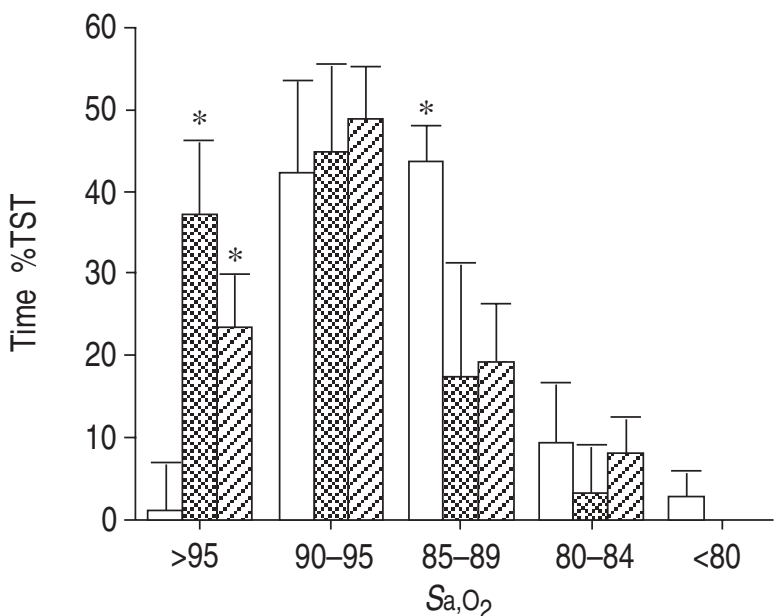

Fig. 1. - Mean ( $\pm \mathrm{SD})$ percentage of total sleep time (TST) spent at each level of arterial oxygen saturation $\left(\mathrm{Sa}, \mathrm{O}_{2}\right)$ during control $(\square)$, low-flow oxygen $(\square)$, and nasal bilevel positive pressure ventilation (NIPPV; $\square$ ). Both oxygen therapy and NIPPV resulted in significantly more sleep time being spent at oxyhaemoglobin saturations $>95 \%$ while significantly less time was spent at low haemoglobin saturations, in particular $<90 \%$. *: $\mathrm{p}<0.05$, versus control.

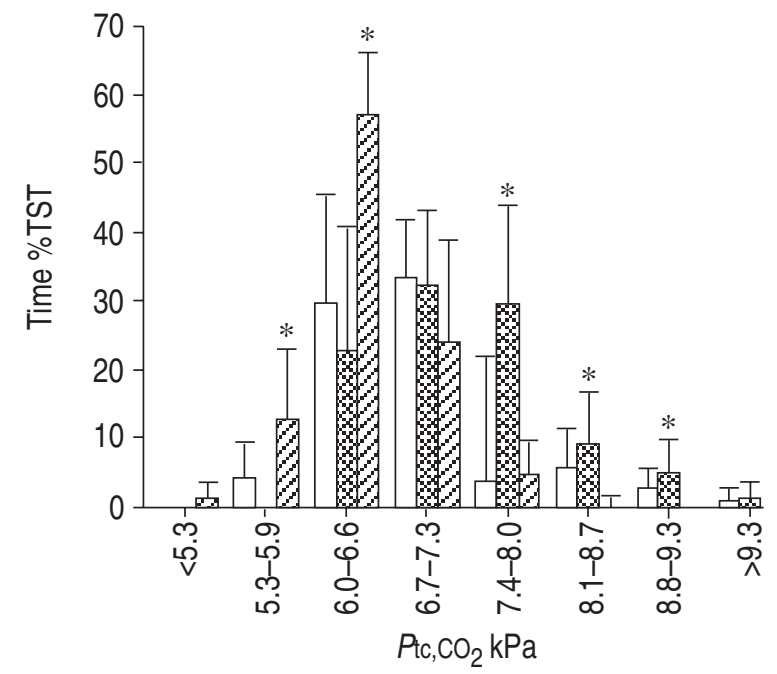

Fig. 2. - Mean ( \pm SD) percentage of total sleep time (TST) spent at each level of transcutaneous $\mathrm{CO}_{2}$ tension $\left(P \mathrm{tc}, \mathrm{CO}_{2}\right)$ during control ( $\square$ ), low-flow oxygen ( $\square$ ), and nasal bilevel positive pressure ventilation (NIPPV; $\square$ ). NIPPV resulted in significantly more sleep time being spent at $P \mathrm{tc}, \mathrm{CO}_{2}<6.7 \mathrm{kPa}$, while in oxygen therapy significantly more time was spent at high $P_{\mathrm{tc}, \mathrm{CO}_{2}}$, in particular 7 7.3. *: $\mathrm{p}<0.05$, versus control.

Table 2. - Sleep architecture in six cystic fibrosis (CF) patients breathing room air, supplemental oxygen, or receiving bilevel noninvasive positive pressure ventilation (NIPPV)

\begin{tabular}{|c|c|c|c|c|}
\hline Sleep measures & Room air & Oxygen therapy & NIPPV & $\mathrm{p}$-value \\
\hline TST min & $378 \pm 49$ & $386 \pm 30$ & $390 \pm 29$ & NS \\
\hline Sleep latency $\min$ & $24 \pm 6$ & $18 \pm 2$ & $23 \pm 4$ & NS \\
\hline NREM min & $228 \pm 36$ & $242 \pm 23$ & $241 \pm 29$ & NS \\
\hline NREM \%TST & $60 \pm 3$ & $63 \pm 3$ & $62 \pm 4$ & NS \\
\hline REM min & $47 \pm 18$ *\# & $70 \pm 30^{*}$ & $57 \pm 23^{\#}$ & $*<0.02 ;{ }^{*}<0.03$ \\
\hline REM \%TST & $12 \pm 3 * \#$ & $18 \pm 7 *$ & $15 \pm 5^{\#}$ & $*<0.02 ;{ }^{\#}<0.03$ \\
\hline Undetermined \%TST & $28 \pm 4$ & $19 \pm 9$ & $24 \pm 6$ & NS \\
\hline Total arousals $\mathrm{h}$ & $49.7 \pm 10.6$ & $38.2 \pm 3.7$ & $47.7 \pm 3.6$ & NS \\
\hline Arousal index & $8.1 \pm 2.6$ & $6.0 \pm 0.8$ & $7.4 \pm 0.7$ & NS \\
\hline $\mathrm{Sa}_{\mathrm{a}, \mathrm{O}_{2}}$ in NREM \% & $88 \pm 5 * \S(80-92)$ & $94 \pm 1 *(92-96)$ & $93 \pm 2 \S(90-95)$ & $* \S<0.001$ \\
\hline $\mathrm{Sa}_{\mathrm{a}, \mathrm{O}_{2}}$ in REM $\%$ & $79 \pm 7 * \S(67-86)$ & $90 \pm 2 *(89-93)$ & $88 \pm 3 \S(85-92)$ & $*<0.001 ; \S<0.008$ \\
\hline$P \mathrm{tc}, \mathrm{CO}_{2}$ in NREM kPa & $6.4 \pm 0.4 * \#(6.1-7.2)$ & $7.1 \pm 0.9 * \S(6.4-8.5)$ & $5.7 \pm 0.4 \$ \#(5.4-6.4)$ & $*<0.02 ; §<0.001 ; \#<0.01$ \\
\hline$P_{\mathrm{tc}, \mathrm{CO}_{2}}$ in $\mathrm{REM} \mathrm{kPa}$ & $6.9 \pm 0.8$ *\# $(6.4-8.3)$ & $7.9 \pm 0.7 * \S(7.3-9.1)$ & $6.0 \pm 0.4 \$ \#(5.7-6.7)$ & $* \S<0.003 ; \#<0.01$ \\
\hline
\end{tabular}

Values are mean \pm SD, and range in parenthesis. TST: total sleep time; NREM: non-rapid eye movement sleep; arousal index: total arousals/TST; $P_{\mathrm{tc}, \mathrm{CO}_{2}}$ : transcutaneous $\mathrm{CO}_{2}$ tension; NS: nonsignificant; *: oxygen therapy versus room air; \#: NIPPV versus room air; §: oxygen therapy versus NIPPV. 
(table 2). As with oxygen therapy, a significant increase in total REM duration occurred with NIPPV $(p<0.03$, Kruskal-Wallis H-test). Mean $\mathrm{Sa}_{\mathrm{a}} \mathrm{O}_{2}$ was significantly improved compared to control during REM $(\mathrm{p}<0.008$, Kruskal-Wallis H-test) and NREM ( $\mathrm{p}<0.001$, KruskalWallis H-test), such that overall oxygen saturations were similar in oxygen therapy and NIPPV $(p=N S)$. In contrast with oxygen therapy, however, significant decreases rather than increases in $P \mathrm{tc}, \mathrm{CO}_{2}$ occurred with NIPPV during REM and NREM epochs (table 2; fig. 2).

\section{Discussion}

The present study shows that NIPPV is as effective as supplemental oxygen in improving moderate to severe CF patients during REM and NREM sleep. Moreover, in contrast with oxygen therapy, which induced significant increases in $P \mathrm{tc}, \mathrm{CO}_{2}$, NIPPV improved ventilation during sleep. The beneficial effects on sleepdisordered breathing were achieved without adversely impacting on sleep architecture or arousal index.

Before discussing our results, some methodological points deserve comment. First, patients were obviously aware of the nature of the intervention being administered during the second and third nights of the study. However, although all participants were familiar with the experimental protocol, they were naive to the actual purpose of the study, and both patients and sleep laboratory technicians were unaware of sleep study results until completion of the third night polysomnographic study. Second, randomization of the treatments during the second and third experimental nights (three patients received oxygen therapy and three received NIPPV during the second sleep study recording) should have prevented a potential preferential bias. Finally, $P \mathrm{tc}, \mathrm{CO}_{2}$ measurements have been reported to drift downwards over time, and changes in electrode position after $4 \mathrm{~h}$ of sleep may modify recorded $P \mathrm{tc}, \mathrm{CO}_{2}$ values [13]. However, such electrode-related artefacts would have affected all our recordings similarly, independent of the treatment being administered. In addition, our precautions to compare actual $P$ tc, $\mathrm{CO}_{2}$ readings with $\mathrm{PCO}_{2}$ values obtained from a capillary blood sample drawn at two different time points of the sleep study further ensure that despite the potential inaccuracy of $P \mathrm{tc}, \mathrm{CO}_{2}$ measurements, the trends obtained throughout the study remain valid.

Daytime oxygen saturation is either not predictive of sleep-related desaturation $[14,15]$ or may actually assist in the prediction of nocturnal hypoxaemia [16]. Irrespective of the value of waking $\mathrm{Sa}_{\mathrm{a}} \mathrm{O}_{2}$ in identifying CF patients at risk for oxyhaemoglobin desaturation during sleep, vulnerable periods during which hypoxaemia is more likely to occur include REM sleep [1, 2, 4, 17] and acute infectious pulmonary exacerbations [18]. Indeed, during REM sleep epochs, significantly lower $\mathrm{Sa}, \mathrm{O}_{2}$ and increased $P \mathrm{tc}, \mathrm{CO}_{2}$ occurred in our patients (table 2), and were possibly mediated by a reduction of functional residual capacity occurring during transition to this sleep stage and reflecting the typical decrease in motor tone which accompanies REM [2, 4].

Our results are in close agreement with SPIER et al. [3], who reported improved oxygenation with supple- mental oxygen and no changes in sleep quality. However, in contrast with SPIER et al. [3], low-flow oxygen was associated with significant increases in $P \mathrm{tc}, \mathrm{CO}_{2}$ in our patients, and two patients reported morning headaches suggestive of clinically significant carbon dioxide retention. Despite the potential for development of severe hypercapnia and the uncertain value of long-term domiciliary oxygen therapy in CF [19], it has been our impression that low-flow oxygen remains the preferred modality of respiratory support by hypoxaemic CF patients. The long-term clinical implications of hypercapnia in these patients are, however, unclear. Indeed, hypercapnia and acidosis may increase pulmonary vascular tone independent of hypoxia [20], and have also been associated with diminished psychosocial function [21]. In addition, repeated hypercapnic episodes alter ventilatory drive [22], and prolonged hypercapnia may blunt $\mathrm{CO}_{2}$ chemosensitivity [23].

The major difference between oxygen therapy and NIPPV treatments was the prevention and amelioration of sleep-related hypercapnia with NIPPV. These findings, and those of REGNIS et al. [4] who found no changes in $P \mathrm{tc}, \mathrm{CO}_{2}$ during nasal CPAP, suggest that NIPPV provides not only mechanical support for the maintenance of upper airway patency and end-expiratory lung volume (EELV), but may also assist in overcoming any EELV-associated increases in elastic load, thereby reducing the work of breathing and possibly allowing for some degree of respiratory muscle rest $[4,6]$. Such inherent advantages of NIPPV could lead, if used regularly, to significant improvements in ventilatory drive [24], daytime functional capacity, and quality of life in $\mathrm{CF}$.

Information regarding potential benefits and experience with NIPPV in patients with COPD in general [2527], and more particularly in CF patients [4], is rather limited. In a recent study of 14 patients with severe COPD, NIPPV with oxygen resulted in significant improvements of daytime blood gases, sleep efficiency, and quality of life when compared to oxygen alone [27]. In this particular study, only one patient withdrew from the study because of intolerance to NIPPV. However, other studies have reported higher intolerance rates to mask ventilation, and different methods have been suggested to achieve optimally comfortable settings [28, 29]. Despite our precautions to ensure habituation to the nasal mask and ventilatory settings, two of our eight patients withdrew from the study. When the remaining six patients were asked about their preferences regarding home therapy, four chose low-flow oxygen. Of the two patients who selected NIPPV for home therapy, one has been relatively noncompliant, while the other reports great satisfaction with his therapy, to which he attributes an increased level of daytime activity and wellbeing. Therefore, although NIPPV demonstrates significant potential for the management of severely compromised CF patients, further studies appear necessary for identification of those patients most likely to accept and comply with such therapeutic modality, and for determination of the short and long-term benefits of such intervention.

In conclusion, noninvasive positive pressure ventilation appears to be as effective as low-flow oxygen in preventing sleep-induced hypoxaemia in severe cystic 
fibrosis patients. Improved oxygenation was achieved without modification of sleep quality and efficiency. An additional and potentially clinically important benefit of noninvasive positive pressure ventilation may lie in the normalized or at least significantly improved alveolar ventilation obtained with noninvasive positive pressure ventilation throughout the night. Despite concerns about reduced patient tolerance and compliance, noninvasive positive pressure ventilation should be entertained as a viable and feasible therapeutic modality in cystic fibrosis patients with advanced lung disease.

Acknowledgement: The author thanks all participants for their enthusiastic co-operation.

\section{References}

1. Tepper RS, Skatrud JB, Dempsey JA. Ventilation and oxygenation changes during sleep in cystic fibrosis. Chest 1983; 84: 388-393.

2. Muller NL, Francis PW, Gurwitz D, Levison H, Bryan AC. Mechanisms of hemoglobin desaturation during rapid-eye-movement sleep in normal subjects and in patients with cystic fibrosis. Am Rev Respir Dis 1980; 121: 463-469.

3. Spier S, Rivlin J, Hughes D, Levison H. The effect of oxygen on sleep, blood gases, and ventilation in cystic fibrosis. Am Rev Respir Dis 1984; 124: 712-778.

4. Regnis JA, Piper AJ, Henke KG, Parker S, Bye PTP, Sullivan CE. Benefits of nocturnal nasal CPAP in patients with cystic fibrosis. Chest 1994; 106:1717-1724.

5. Avital A, Sanchez I, Holbrow J, Kryger M, Chernick V. Effect of theophylline on lung function tests, sleep quality, and night-time $\mathrm{Sa}_{\mathrm{a}} \mathrm{O}_{2}$ in children with cystic fibrosis. Am Rev Respir Dis 1991; 144: 1245-1249.

6. Claman DM, Piper A, Sanders MH, Stiller RA, Votteri BA. Nocturnal noninvasive positive pressure ventilatory assistance. Chest 1996; 110: 1581-1588.

7. DuBois AB, Botello SW, Comroe JH. A new method for measuring airways resistance in man using body plethysmography: values in normal subjects and in patients with respiratory disease. J Clin Invest 1956; 35 : 327-335.

8. Platzker ACG, Keens TG. Pulmonary function testing in pediatric patients. In: Wilson AF, ed. Pulmonary Function Testing: Indications and Interpretations. New York, Grune and Stratton, 1985; pp. 275-292.

9. Marcus CL, Omlin KJ, Basinski DJ, et al. Normal polysomnographic values for children and adolescents. Am Rev Respir Dis 1992; 146: 1235-1239.

10. Indications and standards for cardiopulmonary sleep studies. Am Rev Respir Dis 1989; 139: 559-568.

11. Young T, Palta M, Dempsey J, Skatrud J, Weber S, Bader $\mathrm{S}$. The occurrence of sleep-disordered breathing among middle-aged adults. N Engl J Med 1993; 328: 1230-1235.

12. Rechtschaffen A, Kales A. A manual of standardized terminology, techniques and scoring systems for sleep stages of human subjects. Washington DC, National Institute of Health, 1968; Publication No. 204.

13. Pradal U, Braggion C, Mastella G. Transcutaneous blood gas analysis during sleep and exercise in cystic fibrosis. Pediatr Pulmonol 1990; 8: 162-167.
14. Coffey MJ, Fitzgerald MX, McNicholas WT. Comparison of oxygen desaturation during sleep and exercise in patients with cystic fibrosis. Chest 1991; 100: 659662.

15. Montgomery M, Wiebicke W, Bibi H, Pagtakhan RD, Pasterkamp H. Home measurement of oxygen saturation during sleep in patients with cystic fibrosis. Pediatr Pulmonol 1989; 7: 29-34.

16. Versteegh FG, Bogaard JM, Raatgever JW, Stam H, Nejens HJ, Kerrebijn KF. Relationship between airway obstruction, desaturation during exercise and nocturnal hypoxemia in cystic fibrosis patients. Eur Respir $J$ 1990; 3: 68-73.

17. Francis PW, Muller NL, Gurwitz D, Milligan DW, Levison H, Bryan AC. Hemoglobin desaturation: its occurrence during sleep in patients with cystic fibrosis. Am J Dis Child 1980; 134: 734-740.

18. Allen MB, Mellon AF, Simmonds EJ, Page RL, Littlewood JM. Changes in nocturnal oximetry after treatment of exacerbations in cystic fibrosis. Arch Dis Child 1993; 69: 197-201.

19. Zinman R, Corey M, Coates AL, et al. Nocturnal home oxygen in the treatment of hypoxemic cystic fibrosis patients. J Pediatr 1989; 114: 368-377.

20. Susmano A, Passovoy M, Carleton RA. Mechanisms of hypercapnic pulmonary hypertension. Cardiovasc Res 1977; 11: 440-445.

21. Barlow PB, Bartlett D Jr, Hauri P, et al. Idiopathic hypoventilation syndrome: importance of preventing nocturnal hypoxemia and hypercapnia. Am Rev Respir Dis 1980; 121: 141-145.

22. Gozal D, Ben-Ari JH, Harper RM, Keens TG. Ventilatory responses to repeated, short hypercapnic challenges. $J$ Appl Physiol 1995; 78: 1374-1381.

23. Berthon-Jones M, Sullivan CE. Time course of change in ventilatory response to $\mathrm{CO}_{2}$ with long-term CPAP therapy for obstructive sleep apnea. Am Rev Respir Dis 1987; 135: 144-147.

24. Garay S, Turino G, Goldring R. Sustained reversal of chronic hypercapnia in patients with alveolar hypoventilation syndrome: long-term maintenance with noninvasive nocturnal mechanical ventilation. Am J Med 1981; 70: 269-274.

25. Carroll N, Branthwaite M. Control of nocturnal hypoventilation by nasal intermittent positive pressure ventilation. Thorax 1988; 43: 349-353.

26. Strumpf DA, Millman RP, Carlisle CC, Grattan LM, Ryan SM, Erickson AD, Hill NS. Nocturnal positivepressure ventilation via nasal mask in patients with severe chronic obstructive pulmonary disease. Am Rev Respir Dis 1991; 144: 1234-1239.

27. Meecham Jones DJ, Paul EA, Jones PW, Wedzicha JA. Nasal pressure support ventilation plus oxygen compared with oxygen therapy alone in hypercapnic COPD. Am J Respir Crit Care Med 1995; 152: 538-544.

28. Rodenstein DO, Stanescu DC, Delguste P, Liistro G, Aubert-Tulkens G. Adaptation to intermittent positive pressure ventilation applied through the nose during the day and night. Eur Respir J 1989; 2: 473-478.

29. Kerby G, Mayer L, Pingleton S. Nocturnal positive pressure ventilation via nasal mask. Am Rev Respir Dis 1987; 135: 738-740. 